\title{
Vietnamese students' problem-solving skills in learning about error of measurements
}

\author{
Tang Minh Dunga \\ Pham Mong Bao \\ aHo Chi Minh City University of Education, VIETNAM \\ bNha Be District Continuing Education Center Highschool, VIETNAM
}

ABSTRACT
Problem-solving is one of the ten core competences that Vietnam's new comprehensive general education program after 2018 focuses on. Based on the following findings that (a) in the history of mathematics, error and statistics have a closely related relationship with each other but in the current mathematic curriculum, they are taught separately, and (b) in Vietnam, there has not been any research on teaching error of measurements in the current curriculum, this research focuses on assessing Vietnamese students' problem-solving skills in dealing with errors using statistical tools. The research was conducted following two paralleled approaches: (1) analyzing academic materials according to praxeological organization in relation to components of problem-solving skills so as to clarify the formation and development of problem-solving skills through the education system, (2) building an experiment of processing errors using statistical tools that students have learned in the curriculum and evaluating the degree of problem-solving skills of a sample of 201 students randomly chosen in Ho Chi Minh City. Research results show that although processing errors using statistics has been presented in Mathematics and Physics textbooks, the majority of student failed to propose a solution in the experiment. The research questions the practical teaching of teachers and teacher training in pedagogical universities as well as provides an evaluation of the reality of the current educational system, contributing to the development of mathematics curriculum and textbook composition after 2018.

KEYWORDS

Problem-solving skills; error; statistics
ARTICLE HISTORY

Received 11 September 2016 Revised 26 November 2016 Accepted 11 February 2017

\section{Introduction}

The history of mathematics shows that the theory of errors and probability statistics are closed related (Boyé et al., 2002). However, in current textbooks in Vietnam, "error" is presented at the beginning of grade 10 and "statistics" at the end of grade 10. This separation (at least, in terms of forms) of the two contents leads to the question: How is teaching errors in relation with

\section{CORRESPONDENCE Minh Dung Tang dungtm@hcmup.edu.vn}

(c) 2017 Tang Minh Dung \& Pham Mong Bao

Open Access terms of the Creative Commons Attribution 4.0 International License apply. The license permits unrestricted use, distribution, and reproduction in any medium, on the condition that users give exact credit to the original author(s) and the source, provide a link to the Creative Commons license, and indicate if they made any changes. (http://creativecommons.org/licenses/by/4.0/) 
statistical tools counted in the current high school curriculum in Vietnam? Through a review of studies about teaching errors in the current Vietnamese mathematics curriculum (Le Thi, 2012; Vu Thi, 2014), in the four types of errors - hypothesis error, method error, calculation error, data error (Le Thai Bao, 2012 ), it is realized that there has been no research about data error (error of measurements).

On the other hand, the Vietnam Ministry of Education and Training is currently developing a new general education program, which is to be implemented after 2018. Different from previous education programs, which mainly focused on knowledge and skill, the focus of this time's reform is on the formation and development of learner's competences necessary for life. In the list of competences, problem-solving is one of the core competences that the program aims to. In such context, it is necessary to reevaluate the formation of problem-solving skills in the current teaching design to draw out necessary experience for the modification and building of the new program after 2018.

Based on the two notes above, the article presents results from the evaluation of Vietnamese high school students' problem-solving in the experiment of "identifying errors of measurement" in relation with statistical knowledge.

\section{Methodological framework}

The research was conducted two paralleled approaches as follows:

1) Analyzing current acamedic materials (curriculum, textbook, teacher's book) of both Mathematics and Physics. This selection is based on the occurance of "errors of measurement" in both subjects.

2) Building an experiment to evaluate problem-solving in the above topic.

The complementation of the two approaches will clarify the causal relationship related to problem-solving. In deed, the first approach is to determine the potential for the formation and development of problem-solving in the current teaching design, in light of which, an explanation of the degree of students' problem solving can be provided. The second approach evaluates the effectiveness of teaching designs in the current curriculum and textbooks for high school students. Below, we provide a more detailed description of research tools utilized in the two approaches.

\section{Praxeological organization}




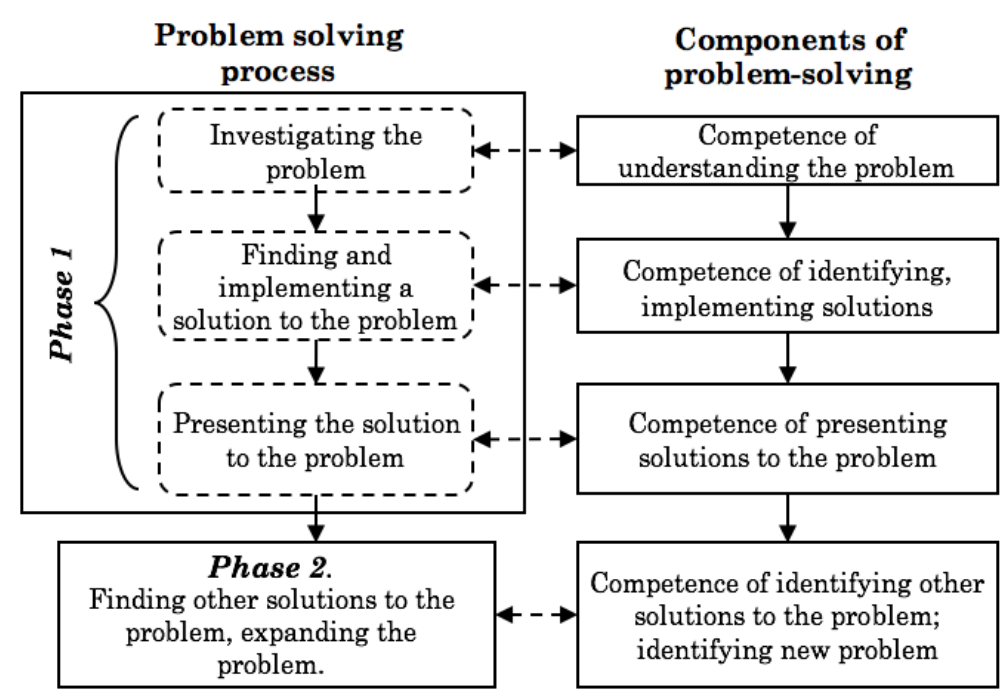

Figure 1. Phases in the problem-solving process and components of problem-solving

According to Phan (2014, p.17), "student's problem-solving skills in learning mathematics is a combination of competences expressed through activities in the problem-solving process". The problem-solving process has two phases with corresponding components as mentioned above (Figure 1).

Since problem-solving skills are expressed through activities, it can be examined by praxeological organizations of anthropological theory of didactics (Chevallard, 1999): "All human activity consists in performing a task $\mathrm{t}$ of a certain type T by means of a technique $\tau$, justified by a technology $\theta$ which at the same time allows it to be thought, or even to produce it, and which in turn is justifiable by a theory $\Theta$ " (Bessot et al., 2009, p.318). Therefore, in order to study problem-solving through learning activities, we need to link components of problem-solving with components, namely $\mathrm{T}, \tau, \theta, \Theta$ of a praxeological organization (Figure 2). Analyzing activities, exercises and theory in the textbooks of Mathematics and Physics with the four variables $[\mathrm{T} / \tau / \theta / \Theta]$ will clarify the appearance of components of problem-solving in teaching designs.

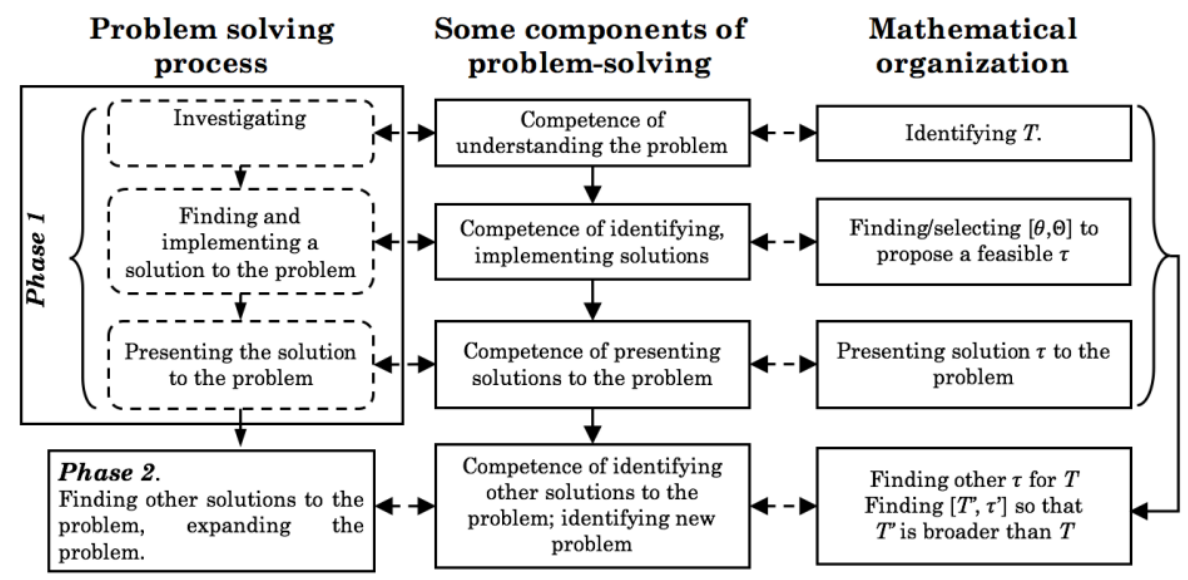


Figure 2. The graph of links between components of problem-solving and components of praxeological oganization

\section{Experiment}

Based on the problem-solving model of Polya (1945), Toh et al (2011) developed the evaluating model of Schoenfeld (1992) to compose the rubric for evaluating problem solving skills. Phan (2014) modified this new rubric to suit the reality of Vietnamese education (see appendix). With this rubric, each step in the problem-solving process of student: Understanding the problem $(\mathrm{H})$, identifying, implementing the solution (P), presenting the solution ( $\mathrm{Tr}$ ), identifying other solutions $(\mathrm{Pk})$, expanding the problem (V) will be evaluated on a given degree. Specifically, during Phase 1 of "Identifying a solution to the problem from separate evaluation $(\mathrm{H}, \mathrm{P}, \mathrm{Tr})$, the researcher can combine these three to generally evaluate the whole phase. In the experimental research, we use this rubric to evaluate student's problem-solving in the following experiement.

Problem: Using a ruler with Inch as the unit of measurement (provided in the experiment), what is the result of the measurement of the height of object A (described in the picture)?

In this problem, on the one hand, we reused the task given in the textbook to evaluate the teaching effectiveness of the current curriculum and textbooks in the formation of components of problem-solving; on the other hand, we modified data of the problem so that "error" can occur clearly in the measurement:

- Selection of design of object A: On the bottom, it is a flat surface but on the top, it is a sphere. This design will make differences when students identify positions of the two ends corresponding to the height of object A using straight ruler.

- A ruler with Inch as the unit of measurement. The division of inch in a straight ruler is bigger than the division of centimeter, hindering students in establishing correspondence between the height of object A and marks on the ruler.

These changes give students an unfamiliar situation. Thereby, they have to show their problem-solving skills.

Next, we organize students into activities with small questions as follows to force students to express each component of problem-solving (Table 1).

Table 1. Procedure of activity organization - question and evaluation

\begin{tabular}{|c|l|l|}
\hline Phase & \multicolumn{1}{|c|}{ Assignment of students } & \multicolumn{1}{|c|}{ Evaluation } \\
\hline \multirow{3}{*}{1} & $\begin{array}{l}\text { Each student measures the height of object A with an inch ruler } \\
\text { on their own to answer question: } \\
\text { 1a) What is the height of object A from your measurement? }\end{array}$ & $\begin{array}{l}\text { Understanding, } \\
\text { with 4 levels (H0; } \\
\text { H1; H2; H3) }\end{array}$ \\
\hline
\end{tabular}




\begin{tabular}{|c|c|c|}
\hline & $\begin{array}{l}\text { After the teacher write all results of measurement on the board, } \\
\text { students answer question: } \\
\text { 1b) Are you sure that your measurement is accurate? Why? } \\
\text { Summarize the problem that needs solving here. (clearly state } \\
\text { the hypothesis and conclusion) } \\
\text { The following phase of experiment is only conducted with } \\
\text { students who give the answer "the measurement is inaccurate". }\end{array}$ & \\
\hline 2 & $\begin{array}{l}\text { Students work individually to answer questions: } 2 a) \text { Since your } \\
\text { measurement is inaccurate, propose a way to write the result of } \\
\text { measurement of the height of object A. } \\
2 b) \text { In your opinion, what allows to propose that way of writing? } \\
\text { The expected way of writing is } \\
\text { "representative value } \pm \text { average absolute error" }\end{array}$ & $\begin{array}{l}\text { Identifying and } \\
\text { implementing the } \\
\text { solution, with } 4 \\
\text { levels (P0; P1; P2; } \\
\text { P3) }\end{array}$ \\
\hline 3 & $\begin{array}{l}\text { Students calculate the repesentative value and the average } \\
\text { absolute error to answer question: } \\
\text { 3) Present the solution that you mentions in your answer to } \\
\text { question } 2 \text { a. }\end{array}$ & $\begin{array}{l}\text { Presenting the } \\
\text { problem, with } 4 \\
\text { levels }(\operatorname{Tr} 0 ; \operatorname{Tr} 1 ; \\
\text { Tr2; } \operatorname{Tr} 3)\end{array}$ \\
\hline \multirow[b]{2}{*}{4} & $\begin{array}{l}\text { Students try to find other solutions to answer question: } \\
\text { 4a) Finding the solutions/anwers different from the solution } \\
\text { that you use to solve the above problem. }\end{array}$ & $\begin{array}{l}\text { Identifying other } \\
\text { solutions with } 2 \\
\text { levels }(\mathrm{Pk} 0 ; \mathrm{Pk} 1)\end{array}$ \\
\hline & $\begin{array}{l}\text { Students try to develop news problems to answer questions: } \\
\text { 4b) The first problem is a specific case of which general } \\
\text { problem? } \\
\text { 4c) Present the solution to a similar problem or the above } \\
\text { general problem. }\end{array}$ & $\begin{array}{l}\text { Identifying new } \\
\text { problems, with } 3 \\
\text { levels (V0; V1; V2) }\end{array}$ \\
\hline
\end{tabular}

The experiment was conducted with $20111^{\text {th }}$ graders (who have finished knowledge about errors and statistics) randomly selected at 3 high schools: Practical High School (Ho Chi Minh City University of Education), Mac Dinh Chi High School and Tay Thanh High School, all are in Ho Chi Minh City, Vietnam. The total time for students to complete the questionnaire in Table 1 was 45 minutes.

It should be noted that in Vietnam, there are currently two textbooks: standard and advanced. However, since almost no school uses the advanced textbook, we only conducted the experiment on students using standard Mathematics and Physics textbooks.

\section{Results and Discussion}

\section{The ability to form problem-solving skills}

The study of errors of measurements using statistical tools in academic materials was conducted via two praxeological organizations as follows (Table 2).

Table 2. Two praxeological organizations of errors of measurements

\begin{tabular}{|l|l|lll|}
\hline & \multicolumn{1}{|c|}{$\begin{array}{c}\text { Praxeological } \\
\text { organization 1 }\end{array}$} & \multicolumn{3}{|c|}{$\begin{array}{c}\text { Praxeological } \\
\text { organization 2 }\end{array}$} \\
\hline $\begin{array}{l}\text { Type } \\
\text { of task }\end{array}$ & $\begin{array}{l}T_{\bar{a}}^{n}: \text { Finding the closest } \\
\text { representative value } \bar{a} \\
\text { for } \quad a_{1}, a_{2}, \ldots, a_{n}\end{array}$ & $\begin{array}{l}T_{\Delta l}^{n} \text { : Finding random error } \Delta l \quad \text { of } \\
\text { representing quantity } a .\end{array} a_{1}, a_{2}, \ldots, a_{n}$ \\
\hline
\end{tabular}




\begin{tabular}{|c|c|c|c|}
\hline & $\begin{array}{l}\text { representing quantity } \\
a .\end{array}$ & & \\
\hline Method & $\begin{array}{l}\tau_{\bar{a}}^{n}: \text { Calculate the mean } \\
\text { of } a_{1}, a_{2}, \ldots, a_{n} \\
\qquad \bar{a}=\frac{a_{1}+a_{2}+\cdots+a_{n}}{n}\end{array}$ & $\begin{array}{l}\tau_{\Delta l-C B}^{n}: \\
\text { - Calculate } \\
\bar{a}=\frac{a_{1}+a_{2}+\cdots+a_{n}}{n} \\
\text { (performing the type of } \\
\text { task } \boldsymbol{T}_{\bar{a}}^{n} \text { presented above } \\
\text { with } a_{1}, a_{2}, \ldots, a_{n} \text { ) } \\
\text { - With each } i=1,2, \ldots, n \text {, } \\
\text { calculate the value } \\
A_{i}=\left|\bar{a}-a_{i}\right| . \\
\text { - If } n \geq 5, \text { calculate } \\
\Delta l=\frac{\mathrm{A}_{1}+\mathrm{A}_{2}+\cdots+\mathrm{A}_{n}}{n} \text { (performing } \\
\text { the type of task } \boldsymbol{T}_{\bar{a}}^{n} \\
\text { presented above with } \\
\left.\mathrm{A}_{1}, \mathrm{~A}_{2}, \ldots, \mathrm{A}_{n}\right) ; \quad \text { calculate } \\
\text { If } \quad n<5, \quad \begin{array}{l}\Delta l=\max A_{i} . \\
1 \leq i \leq n\end{array}\end{array}$ & $\begin{aligned} & \boldsymbol{\tau}_{\Delta l-N \boldsymbol{c}}^{n}: \text { Calculate } \\
& \Delta l=\frac{\max _{1 \leq i \leq n} a_{i}-\min _{1 \leq i \leq n} a_{i}}{2}\end{aligned}$ \\
\hline Technology & $\begin{array}{l}\boldsymbol{\theta}_{\bar{a}}^{\boldsymbol{n}} \text { (in standard Physics } \\
\text { textbook for grade 10, } \\
\text { page 41): Definition of } \\
\text { "the closest to real } \\
\text { value of the quantity a" } \\
\text { through the mean of } \\
\text { values }\end{array}$ & $\begin{array}{l}\boldsymbol{\theta}_{\Delta l-C \boldsymbol{B}}^{\boldsymbol{n}} \text { (in standard Physics } \\
\text { textbook for grade 10, } \\
\text { pages } 41-42 \text { ): Definition of } \\
\text { the average absolute error } \\
\text { in the two cases } n \geq 5 \text { and } \\
n<5 \text {. }\end{array}$ & \\
\hline Theory & & $\begin{array}{l}\Theta_{\Delta l-C B}^{n} \text { (in the standard } \\
\text { Physics textbook for grade } \\
\text { 10, page 48): Two axioms of } \\
\text { Gauss's theory of random } \\
\text { errors: } \\
\text { - Errors with equal } \\
\text { absolute values and are } \\
\text { opposite, have the same } \\
\text { statistics of occurance. } \\
\text { - Errors with bigger } \\
\text { absolute values have the } \\
\text { least statistics of } \\
\text { occurance. }\end{array}$ & \\
\hline
\end{tabular}

The presence of mathematical organization in the current Vietnamese education system is briefly described in Table 3 as follows.

Table 3. The presence of mathematic organization about "error of measurement" in academic materials

\begin{tabular}{|c|c|c|c|}
\hline \multirow{2}{*}{$\begin{array}{c}\text { Praxeological } \\
\text { organization }\end{array}$} & \multicolumn{2}{|c|}{ Secondary school } & High school \\
\cline { 2 - 4 } & Physics 6 & Math & Physics 10 \\
\hline
\end{tabular}




\begin{tabular}{|l|c|c|c|c|c|c|}
\hline & & 7 & \multicolumn{2}{|c|}{ Standard } & \multicolumn{2}{c|}{ Advanced } \\
\hline \hline Task & $T_{\bar{a}}^{n}$ & $T_{\bar{a}}^{n}$ & $T_{\bar{a}}^{n}$ & $T_{\Delta l}^{n}$ & $T_{\bar{a}}^{n}$ & $T_{\Delta l}^{n}$ \\
\hline Method & $\tau_{\bar{a}}^{n}$ & $\tau_{\bar{a}}^{n}$ & $\tau_{\bar{a}}^{n}$ & $\tau_{\Delta l-C B}^{n}$ & $\tau_{\bar{a}}^{n}$ & $\tau_{\Delta l-\mathrm{NC}}^{n}$ \\
\hline Technology & & & $\theta_{\bar{a}}^{n}$ & $\theta_{\Delta l-C B}^{n}$ & & \\
\hline Theory & & & & $\Theta_{\Delta l-C B}^{n}$ & & \\
\hline
\end{tabular}

Contrasting with components of problem-solving (Figure 2), we draw out some remarks as follows.

Students are given the chance to develop the compentence of understanding the problem due to tasks $T_{\bar{a}}^{n}, T_{\Delta l}^{n}$ are clearly introduced in textbooks for Physics 6, Math 7, and Physics 10.

Students using standard textbooks can develop the competence of identifying, implementing a solution to the problem since technology factors $\theta_{\bar{a}}^{n}$ và $\theta_{\Delta l-C B}^{n}$ have been introduced in textbooks. It is known that $\tau_{\bar{a}}^{n}$ and $\tau_{\Delta l-C B}^{n}$ methods only retain in teacher's instructor while the methods are not remind in examples of student's textbooks. Via the absent of factor, it makes students really difficult to present the solutions of the problem.

\section{Evaluating the degree of students' problem-solving skills}

In this section, we present results of the classification of 201 answers from students in the experiment to evaluate the problem-solving skills (detailed figures are presented in the appendix).

During phase 1 "Identifying a solution to the problem", most provided incorrect solution (115 students, accounting for $57 \%$ ) or partially correct solution (69 students, accounting for 33\%). This shows that the degree of Vietnamese students' problem-solving in identifying data error through statistical tools is still low.

Next, we examine in details the degree of component competences in this stage (Table 4).

Table 4. Evaluating components of the problem-solving in the phase

"Identifying a solution to the problem" of 201 students in the experiment

\begin{tabular}{|c|c|c|c|c|c|}
\hline $\begin{array}{r}\text { Competen } \\
\text { th }\end{array}$ & $\begin{array}{l}\text { derstanding } \\
\text { em }\end{array}$ & $\begin{array}{l}\text { Compete } \\
\text { implement }\end{array}$ & $\begin{array}{l}\text { lentifying, } \\
\text { lution to the } \\
\text { n }\end{array}$ & $\begin{array}{r}\text { Compete } \\
\text { solutio }\end{array}$ & $\begin{array}{l}\text { esenting a } \\
\text { problem }\end{array}$ \\
\hline Degree & Quantity & Degree & Quantity & Degree & Quantity \\
\hline \multirow{4}{*}{ H3 } & \multirow{4}{*}{13} & \multirow{4}{*}{ P3 } & \multirow{4}{*}{1} & Tr3 & 0 \\
\hline & & & & $\operatorname{Tr} 2$ & 1 \\
\hline & & & & $\operatorname{Tr} 1$ & 0 \\
\hline & & & & Tr0 & 0 \\
\hline
\end{tabular}




\begin{tabular}{|c|c|c|c|c|c|}
\hline & & \multirow{3}{*}{ P2 } & \multirow{3}{*}{6} & $\operatorname{Tr} 2$ & 2 \\
\hline & & & & $\operatorname{Tr} 1$ & 2 \\
\hline & & & & Tr0 & 2 \\
\hline & & \multirow{2}{*}{$\mathrm{P} 1$} & \multirow{2}{*}{6} & $\operatorname{Tr} 1$ & 4 \\
\hline & & & & Tr0 & 2 \\
\hline & & P0 & 0 & Tr0 & 0 \\
\hline \multirow{6}{*}{$\mathrm{H} 2$} & \multirow{6}{*}{73} & \multirow{3}{*}{ P2 } & \multirow{3}{*}{22} & $\operatorname{Tr} 2$ & 4 \\
\hline & & & & $\operatorname{Tr} 1$ & 18 \\
\hline & & & & Tr0 & 0 \\
\hline & & \multirow{2}{*}{ P1 } & \multirow{2}{*}{24} & $\operatorname{Tr} 1$ & 24 \\
\hline & & & & $\operatorname{Tr} 0$ & 2 \\
\hline & & P0 & 27 & Tr0 & 27 \\
\hline \multirow{3}{*}{ H1 } & \multirow{3}{*}{91} & \multirow{2}{*}{$\mathrm{P} 1$} & \multirow{2}{*}{42} & $\operatorname{Tr} 1$ & 17 \\
\hline & & & & Tr0 & 25 \\
\hline & & P0 & 49 & Tr0 & 49 \\
\hline H0 & 24 & P0 & 24 & Tr0 & 24 \\
\hline
\end{tabular}

Monitoring changes in the degree in steps in phase 1 helps us draw out some explanations about the above classification of Vietnamese students as follows. 24 students (accounting for 12\%) wrongly understood the problem (they stated that their measurements were correct), which, in turn, led to the failure in implementing succeeding problem-solving steps. 13 students (accounting for $6 \%)$ correctly understood the problem, but there was only one student able to point out and present completely the solution of the problem. For the rest of the students, most of them (164 students, accounting for 82\%) were unable to understand completely the problem (not using learned knowledge about errors, not providing the way to write "the representative value \pm the average absolute error"), which reducing from half to one third of the number of students that could propose a solution to the problem. It is possible that although "errors ans statistical" is taught in grade 10 , students did not usually have the change to review and apply it in grade 11 so they don't remember it.

During phase 2, 35 students (accounting for 17\%) proposed another solution to the problem such as increasing the number of measurements, more careful measurement; especially, 8 students suggested the method $\tau_{\Delta l-N C}^{n}$ to calculate $\Delta l$ (although students in the experiment only used standard textbooks, in other words, they were only taught the method $\tau_{\Delta l-C B}^{n}$ ). 
For the task of expanding the problem, 51 students (accounting for 25\%) proposed a new problem without a correct solution. For example, 48 students generalized the experimental problem into the problem of errors in measurements (with other objects such as the thickness of a book, the diameter of a ball, the amount of time for dropping an object); 17 students proposed an intervention of statistics since they recorded that the range $(\bar{a}-\Delta l ; \bar{a}+\Delta l)$ could not contain all measured values $a_{i}$ of students in the class, in light of which, it is necessary to have a certain accurate statistics so that the values of measurements can fall in the above range.

Therefore, it can be observed that few students could reach phase 2 "Finding other solutions and expanding the problem". On the other hand, answers from students also showed the ability to connect the task of processing errors (statistics) with statistical thinking of the situation designed in the experiment.

\section{Conclusion}

Although knowledge related to processing errors of measurements through statistics has been officially introduced to students, experiment shows that students are not familiar with this requirement. It seems that the problemsolving skills in errors of measurements is not clearly present in the teaching practice of teachers. In light of which, this research can open up new directions for studies related to teachers' teaching practice about "random errors" and building up a didactic engineering for students to form and develop problemsolving skills in errors of measurements, which are very common in experimental sciences (physics, chemistry, etc.).

On the other hand, the research also provides some instructions for building and preparing for the new curriculum in Vietnam after 2018 following the competence development approach, related to "data of measurements" and expanding to other types of errors as well. Firstly, it is necessary to increase the interdisciplinary connection (Math and Physics, for instance) so that students can understand clearly the meaning of mathematical knowledge through problems encountered in reality (errors in measurements). Secondly, teacher training should be focused on the formation and development of problem-solving and an understanding that is deep in terms of major knowledge (mathematical statistics), and broad in terms of relevant sciences (theory of errors).

\section{Disclosure statement}

No potential conflict of interest was reported by the authors.

\section{Notes on contributors}

Tang Minh Dung, Doctor of Mathematics and Informatics, Lecturer of the Department of Mathematics and Information Technology, Ho Chi Minh City University of Education, Ho Chi Minh City, Viet Nam.

Pham Mong Bao, Master of Mathematics Education, Teacher of Mathematics, Nha Be District Continuing Education Center Highschool, Ho Chi Minh City, Viet Nam. 


\section{References}

Bessot, A., Comiti, C., Le Thi, H. C. \& Le Van, T. (2009). Elements fondamentaux de didactique des mathématiques. Ho Chi Minh City: Ho Chi Minh City National University Publisher.

Boyé, A. \& Comairas, M.-C. (2002) Moyenne, mediane, écart-type. Quelques regards sur l'histoire pour éclairer l'enseignement des statistiques. Repères-IREM, 48, 27-40.

Chevallard, Y. (1999). Analyse des pratiques enseignantes en théorie anthropologique du didactique. Recherche en didactique des mathématiques, 19(2), 221-265.

Le Thai Bao, T. T. (2012) Approximate number in high school mathematics education. Journal of Science - Special Issue: Education science (Ho Chi Minh City University of Education), 37, 103-113

Le Thi, B. H. (2012) Nghiên cứu didactic sự nối khớp giữa máy tính bỏ túi và xấp xỉ thập phân trong phép tính số: Trường hợp giải tam giác (Master's Thesis). Ho Chi Minh city: Ho Chi Minh City University of Education.

Phan, A. T. (2014) Assessment of the problem-solving ability of the students in teaching grade 11 mathematics at middle school (PhD Thesis). Vinh: Vinh University.

Polya, G. (1945). How to solve it. Princeton, NJ: Princeton University Press.

Schoenfeld, A. H. (1992). Learning to think mathematically: Problem-solving, metacognition, and sense making in mathematics. In D. A. Grouws (Ed.) Handbook of research on mathematics teaching and learning (pp.334-370). New York: Macmillan.

Toh, T. L., Quek, K. S., Leong, Y. H., DinDyal, J. \& Tay, E. G. (2011) Assessing problem-solving in the mathematics curriculum: A new approach. In B. Kaur, \& K. Y. Wong (Eds.) Assessment in the mathematics classroom: Association of Mathematics Educators 2011 Yearbook (pp.3366). Singapore: World Scientific.

Vu Thi, T. T. (2014) Một nghiên cứu về số gần đúng và sai số trong dạy học toán ở bậc phổ thông (Master's Thesis). Ho Chi Minh City: Ho Chi Minh City University of Education.

\section{Appendix}

Statistical figure of the number of students' answers on the degree of problem-solving

\section{Phase 1: Identifying a solution to the problem}

\begin{tabular}{|l|c|l|r|r|}
\hline $\begin{array}{c}\text { Level of the } \\
\text { solution to the } \\
\text { problem }\end{array}$ & Degree of competence & \multicolumn{2}{|c|}{ Criterion } & \multicolumn{2}{|c|}{$\begin{array}{c}\text { Number of } \\
\text { questions }\end{array}$} \\
\hline \multirow{2}{*}{ Correct solution } & 4 & H3 - P3 - Tr3 & 0 \\
\cline { 2 - 4 } & 3 & H3 - P3 - Tr2 & 1 & \\
\cline { 2 - 5 } & 2 & H3 - P3 - Tr1 & 0 & \\
\cline { 2 - 5 } & 1 & H3 - P3 - Tr0 & 2 & 14 \\
\hline \multirow{2}{*}{$\begin{array}{l}\text { Partially wrong } \\
\text { solution }\end{array}$} & 4 & H3 - P2 - Tr2 & H3 - P2 - Tr1 & \\
\cline { 2 - 5 } & 3 & H3 - P2 - Tr0 & 2 & \\
\hline
\end{tabular}




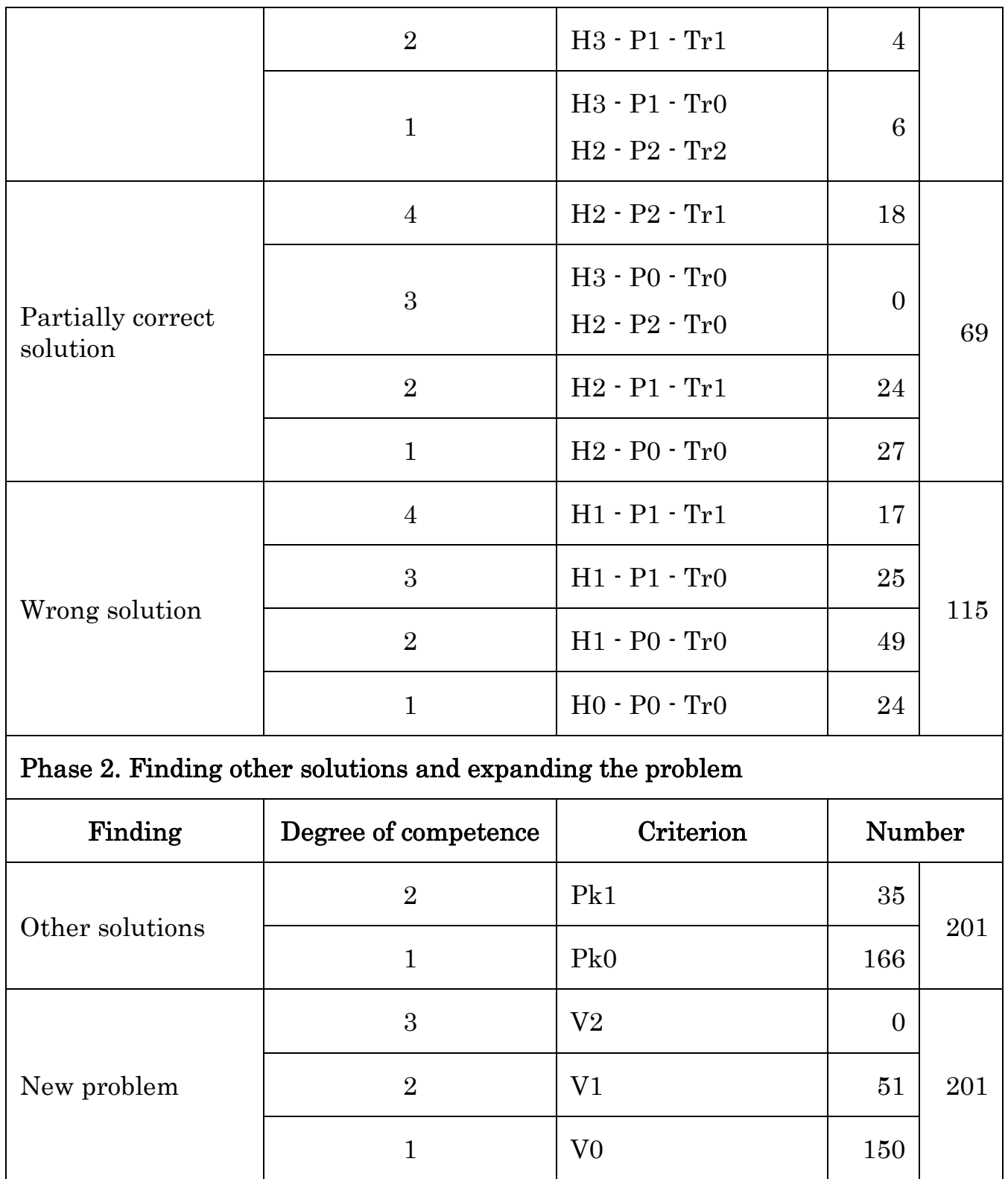

In the above table, criteria are codified as follows:

$\mathrm{H}$ : Competence of understanding the problem, with four levels:

- H3: Students demonstrate that they correctly identify the problem; correctly identify information (hypothesis), requirement (conclusion) of the problem, correctly draw the shape (if required); correctly write conditions in the form of formula when neccesary.

- H2 : Students only wrongly understand a maximum of one third of the contents of the problem.

- H1 : Students only correctly understand a maximum of one third of the contents of the problem. 
- H0 : Students wrongly understand the problem.

P: Competence of identifying, implementing a solution to the problem, with four levels:

- P3 : Students propose a correct solution: correctly analyzing the relationship between data and requirement of the problem; mobilizing correct knowledge, skills; discovering a correct solution, implementing a solution that leads to a correct result (feasible).

- P2 : Students propose a solution that solve at least two thirds of the contents of the problem.

- P1 : Students propose a solution that solve at maximum one third of the contents of the problem.

- P0 : Students propose a wrong solution or no solution at all.

Tr: Competence of presenting a solution to the problem, with four levels:

- Tr3 : Students present a solid and logical argument; accurate calculation.

- Tr2 : Students present a loose and not really logical argument; not completely accurate calculation.

- $\operatorname{Tr} 1$ : Students present a unsolid and illogical argument; inaccurate calculation.

- Tr0 : Students almost present no argument, fail to calculate.

Pk: Competence of finding other solutions to the problem, with two levels

- Pk1 : Students propose other correct solutions.

- $\mathrm{Pk} 0$ : Students propose extra but incorrect solutions or no other solution at all.

V: Competence of identifying new problems, with three levels

- V2 : Students are able to identify similar problems or a general problem correctly and direct correct solutions to the problem.

- V1 : Students are able to identify similar problems or a general problem correctly but have no direction for solutions to the problem or direct incorrect solutions to the problem.

- V0 : Students fail to identify similar problems or a general problem. 